\title{
¿Los créditos compulsivos deterioraron económicamente a los mercaderes españoles? Nueva información para el caso Córdoba (1806-1830)
}

\author{
Félix E. Converso \\ CNIC y Universidad Nacional de Córdoba, \\ Argentina
}

A la luz de nueva información, se revisa la tradicional versión historiográfica que atribuye a la política del crédito compulsivo aplicado al comercio de Córdoba, y en particular a sus agentes españoles, la resultante de un deterioro económico. Esta es una interpretación originada en fuentes cualitativas, que no refleja la real dimensión del impacto sobre el peculio de los aludidos mercaderes. El estudio de otras fuentes permite inferir una situación bien distinta.

Nuestra historiografía referida al tema de las exacciones dinerarias y al crédito más o menos compulsivo en relación a americanos y españoles residentes en la antigua jurisdicción del virreinato del Río de la Plata, coincide en dedicar especial atención a aquellas disposiciones de la Asamblea del año XIII o del Congreso de Tucumán, ${ }^{1}$ omitiendo —con algunas contadas excepciones- lo acon-

1 Duarte, María Amalia: Contribuciones y empréstitos de San Miguel de Tucumán, Santiago del Estero y Catamarca a los gastos de la Independencia (1810-1815). Leoni Pinto, Ramón: Empréstitos y comercio en Tucumán. Introducción a su estudio 1810-1825. Segreti, Carlos S. A.: La misión Jonte-Ugarteche 1813-1814 (Un intento de reactivación económico-financiera del interior), en: "Academia Nacional de la Historia, Primer Congreso de Historia Argentina, Nacional y Regional", Buenos Aires, 1973. Emiliani Fozzatti, Jorge R.; Salas, Elsa: El empréstito forzoso sancionado por el soberano Congreso de 1816 a los españoles europeos de Córdoba, en: "Academia Nacional de la Historia, Cuarto Congreso Internacional de Historia de América", Tomo IV, Buenos Aires, 1966, págs. 299 a 322. Cuccorese, Horacio Juan: Economía y finanzas durante la época del Congreso de Tucumán. Buenos Aires, 1969. Galmarini, Hugo Raúl: La situación de los comerciantes españoles después de 1810, "Revista de Indias", XLIV, Madrid, 1984. Inclusive Halperin Donghi, Tulio: Guerra y finanzas en los origenes del Estado argentino (1791-1850), Buenos Aires, 1982, aunque cronológicamente es más extenso, su enfoque con punto de partida en Buenos Aires, le quita mayor amplitud al problema. 
tecido en años anteriores y posteriores, como si los mercaderes españoles hubiesen existido sólo incidentalmente o las causas y secuelas de estas operaciones se extinguiesen en dichos episodios.

Asimismo, puede objetarse a algunos de los artículos aludidos la tendencia a hacer fluctuar la sensación o sospecha de deterioro económico casi irreversible de los pueblos, su comercio y los españoles europeos afectados por las referidas medidas financieras. Ciertamente en algo los menoscabaron, pero esa idea no puedo compartirla en su totalidad. Es en razón de ello que esta propuesta se emprende con el ánimo de revisar la temática, que para el caso de Córdoba exhibe matices diferentes, posibles de vislumbrar al ofrecer un tratamiento con períodos cronológicos más largos que permitan estudiar un más amplio espectro del problema, reunir una mayor y más variada gama de información, tratando de equilibrarla con la debida estimación de los diversos aspectos, procurando expurgar algún "tremendismo" que campea en fuentes un tanto equívocas.

Hipérboles ante las cuales resulta congruente formular el sencillo planteamiento consistente en que ninguna administración, por muy "desesperada" que se encuentre ante los gastos de guerra inesperados, podría inclinarse o decidirse por imponer disposiciones $o$ proyectos financieros que arruinasen a quienes en definitiva canalizaron la mayor fuente de ingresos al fisco, ${ }^{2}$ con el solo propósito de paliar situaciones si bien urgentes, de corte coyuntural algunas y muy circunstancial otras.

\section{Dos elementos concatenantes a tener en cuenta}

El sector mercantil - por efectos de su propia actividad- generó cierto flujo de pequeños capitales. En función de poseedor y traficador de los mismos fue requerido por el Estado para satisfa-

2 Converso, Félix E.: Fisco, finanzas y comercio regional -Córdoba 1810-1835, ponencia presentada en las Novenas Jornadas de Historia Económica. Universidad Nacional de Buenos Aires, 1988 (Mimeo). 
cer sus urgencias fiscales, usualmente mediante dos procedimientos: la vía impositiva y el crédito público.

En razón de la frecuencia con que las necesidades del físco fueron provocadas por la incidencia en el gasto público de las erogaciones militares, éstas y las consecuentes falencias fiscales pueden considerarse dos elementos concatenantes de un mismo fenómeno, que no conviene separar del análisis de su incidencia en el grupo mercantil de Córdoba.

\section{Consideraciones socio-demográficas y patrimoniales}

La ponderable entidad en cuanto a conformación socio-demográfica y patrimonial que exponen los mercaderes españoles radicados en Córdoba en las primeras décadas del siglo XIX deben ser instrumentos de permanente y dinámica atención, al intentar interpretar la repercusión de las disposiciones financieras emanadas de los ámbitos estatales - ya sea de jurisdicción virreinal y nacional o provincial después - habida cuenta de los lazos y ramificaciones parentales, como asimismo comerciales, que originados a fines del siglo XVIII, se consolidaron a lo largo de la primera mitad de la centuria decimonónica. ${ }^{3}$

Aunque se comprueba que durante el decenio de 1820 la población mercantil ibérica instalada en Córdoba disminuyó y presentó exigua renovación, no puede ignorarse su persistencia, cuya vigencia se aprecia aún en los años siguientes. La información disponible ${ }^{4}$ permite afirmar la consistencia de este estamento constituido por una población caracterizada por su edad madura que habiéndose arraigado en la ciudad, constituyó familia y se consolidó en sus negocios y relaciones. A la vez que el medio social dejó de consi-

3 Converso, Félix E.: Españoles y americanos, agentes de un mercado regional, “Anuario de Estudios Americanos", T. XLVII, Sevilla, 1990, págs. 279-307. En este artículo estudio la formación de los lazos parentales y comerciales entre españoles y americanos dedicados al comercio, en Córdoba, durante la primera mitad del siglo XIX.

4 Archivo Histórico de la Provincia de Córdoba (en adelante AHPC), 1813, Gobierno, Censo, Ciudad, 1820, Caja 70, fols. 28 a 35. 1822, Censo Ciudad, Tomo I, 1832, Caja 129, fols. 201 a 419. Archivo General de la Nación (en adelante AGN), Sala X, 5-3-4. 
derarlos "estantes" para pasar a formar parte del vecindario y del quehacer comercial de Córdoba, en ellos se los encuentra en interesante número, bien avanzada la década de 1830 .

La reconstrucción de los indicadores que permiten conocer la cuantía patrimonial de algunos comerciantes españoles (confrontar cuadro $n .^{\circ}$ 1) pauta el acrecentamiento logrado durante las primeras décadas del siglo. Crecimiento obtenido aún corriendo los riesgos de inversión necesarios para obtener riqueza, que si bien nace de los ahorros, éstos requieren -en casos normales- unas rentas considerables que no se consiguen sin exponer capital.

En esta capacidad afrontaron su actividad reinvirtiendo sus beneficios en mercancías ultramarinas y traficando efectos de la tierra. Pero la reducción del giro comercial en las postrimerías del siglo XVIII, influyó negativamente en el hasta entonces importante tráfico de mulas. ${ }^{5}$ Situación agravada por los enfrentamientos bélicos sostenidos con las fuerzas realistas en la región norteña luego de acaecida la revolución de 1810, belicismo que provocó el entorpecimiento de las vías transitadas, descalabrando los acostumbrados intercambios mantenidos con algunas plazas regionales. ${ }^{6}$ Estos incidentes no perduraron o fueron superados gradualmente y el sector mercantil de Córdoba continuó su actividad reorientándose hacia el único gran mercado que permanecía, es decir el puerto de Buenos Aires y por vía ultramarina a los fondeaderos europeos. ${ }^{7}$

5 Oficio del gobernador intendente marqués de Sobremonte, 1785, en: Junta Provincial de Historia de Córdoba, Córdoba, Ciudad y Provincia (siglos XVI a XX) Relatos de viajeros y otros testimonios, (Selección y advertencia de Carlos S. A. Segreti), Córdoba, 1973, pág. 184. Correspondencia de Andrés Santa Coloma a Bernardo Correa de 20 de septiembre de 1779 y 20 de septiembre de 1792, citada por Segreti, Carlos S. A.: El partido español. La facción alzaguista, "Anuario del Departamento de Historia", Año I, n. ${ }^{\circ}$ 1, Córdoba, 1963.

6 AHPC, 1808-1810, Protocolo de Escribanos, Registro n. ${ }^{\circ}$ 1, fols. 537 a 539. Registro . $^{\circ} 4$, fol. 570. 1811-1813, Registro n. ${ }^{\circ} 4$, fols. 253, 254. 1814, Escribanía n. ${ }^{\circ} 4$, Legajo 47, Tomo 1. Expediente 17. Archivo de la Municipalidad de Córdoba (en adelante AMC), Actas Capitulares, Libros 45 y 46, Córdoba, 1960, pág. 465. AGN, Comisionados Jonte y Ugarteche a las provincias interiores, 1813-1814, División Gobierno, Sala X.

7 Lobos, Héctor R.: La revolución y el comercio interior. Análisis de la desintegración del mercado virreinal rioplatense a partir del caso cordobés, "Anuario de Estudios Americanos", XLVII, Sevilla, 1990, págs. 399-495. Converso, Félix E.: Relaciones del intercambio, acrecentamiento patrimonial e inversión del capital comercial, "Cuadernos del Centro de Estudios Históricos", n. ${ }^{\circ}$ 2, Córdoba, 1991. 
CuAdro N. ${ }^{\circ} 1$

\section{ACRECENTAMIENTO PATRIMONIAL DE ALGUNOS COMERCIANTES ESPAÑOLES (EN PESOS DE OCHO REALES) ${ }^{8}$}

\begin{tabular}{lcrrrrr} 
Comerciante & Año & Patrimonio & Año & Patrimonio & $A$ & $B$ \\
\hline González, Felipe Antonio & 1772 & 7.352 & 1802 & 33.939 & 30 & 450,5 \\
Sáenz Bravo, Gaspar & 1789 & 59.395 & 1817 & 206.562 & 28 & 347,7 \\
Fragueiro, Antonio Benito & 1791 & 24.648 & 1812 & 104.362 & 21 & 423,4 \\
Roca, Felipe & 1794 & 2.370 & 1830 & 17.511 & 36 & 738,8 \\
Recalde, Francisco de & 1798 & 17.608 & 1821 & 67.622 & 23 & 384 \\
López, Manuel & 1800 & 17.458 & 1827 & 27.966 & 27 & 160,1 \\
Carrera, Bartolomé & $?$ & 3.000 & 1828 & 37.405 & $?$ & $1.246,4$ \\
Signo, Juan del & 1804 & 20.072 & 1822 & 20.075 & 20 & 0 \\
Lastra, Rosendo & 1809 & 13.000 & 1848 & 19.864 & 37 & 152,8 \\
Cires, Pablo & 1810 & 3.580 & 1820 & 12.782 & 10 & 357 \\
Garzón y Miguel, Félix & 1832 & 2.900 & 1864 & 42.858 & 32 & $1.477,8$ \\
Garzón, José & 1845 & 6.700 & 1858 & 15.000 & 13 & 223,8 \\
Lastra, Manuel de la & 1845 & 33.650 & 1858 & 71.000 & 13 & 210,9 \\
Castellanos, Andrés & 1845 & 8.000 & 1860 & 14.804 & 15 & 185
\end{tabular}

* Declaración impositiva.

$\mathrm{A}=$ Lapso transcurrido en años. $\mathrm{B}=\mathrm{Acrecentamiento} \mathrm{porcentual.}$

Fuente: Elaboración propia según datos de nota 8.

8 En mi artículo Españoles y americanos... se establece el patrimonio de un sector indicativo de comerciantes españoles, utilizando la información referida al capital aportado por ellos al matrimonio. En el Cuadro $n .{ }^{\circ} 1$, se calcula el acrecentamiento patrimonial de algunos de ellos tomando preferencialmente aquellos datos y los relativos a valuaciones especificadas en los sucesorios tramitados al fallecer el comerciante español. Cuando estos datos no se consiguieron se recurrió a declaraciones de bienes requeridas por el fisco, las que siempre conviene tomar con precaución porque el comercio acostumbró disminuir u ocultar los valores por obvias raziones. AHPC, Protocolo de Escribanos, Registro n. ${ }^{\circ} 1,1778$, Tomo 161 , fols. 84 a 86. 1783, Tomo 166, fols. 167, 168. Registro n. ${ }^{\circ}$ 2, 1798, Tomo 7, fols. 67 a 77, Escribanía n. ${ }^{\circ} 1$, 1854, Legajo 490. Escribanía n. ${ }^{\circ} 2$, 1821, Legajo 115, Expediente 9. 1830 1831, Legajo 125. 1849, Legajo 145, Expediente 13. 1850, Legajo 146, Expediente 22. Escribanía n. ${ }^{\circ}$ 3, 1822, Legajo 71, Expediente 3. Escribanía n. ${ }^{\circ} 4$, 1831, Legajo 73, Expediente 3. Instituto de Estudios Americanistas. Fondo documental (en adelante IEA). Documentos n. ${ }^{\text {os }} 3678,3679,3680,3682,3689$. AHPC, 1845, Gobierno, Tomo 197, fols. 360, 361. 1858, Hacienda, Tomo 655 , fols. 47 a 59 . 


\section{Antes y después de 1810}

La gobernación intendencia de Córdoba del Tucumán sobrellevó la estructura administrativa virreinal sin importantes variaciones hasta la década de 1820. Por lo tanto la tesorería cordobesa funcionó subordinada a su similar de Buenos Aires, organización que generó perturbaciones en la funcionalidad del sistema al repercutir negativamente en los intereses y necesidades tanto locales como regionales.

Las invasiones inglesas conforman un interesante punto de referencia -elegido con miras instrumentales - para comenzar a visualizar los procedimientos financieros diseñados no siempre en función del segmento de población al que afectaron y menos aún meditados con la requerida circunspección para obviar los negativos efectos que pudieron implicar.

$\mathrm{Al}$ efectuarse el primer ataque inglés al puerto bonaerense, el virrey Sobremonte ordenó medidas de índole militar tendentes a equipar una expedición con fines de socorro. ${ }^{9} \mathrm{Su}$ implicación financiera consistió en reunir lo necesario para avituallar el proyectado contingente. El comercio, alarmado ante la alternativa de ser incorporado al servicio de las armas - que importaba el abandono de sus negocios- o contribuir con metálico y especie, no trepidó en aportar bienes valuados entre 6.000 y 7.000 pesos. $^{10}$

Estos requerimientos se reiteraron posteriormente a través del Consulado y del Cabildo de Buenos Aires. " Con renuncia manifiesta, el comercio donó 3.621 pesos sobre un total de 4.569 pesos reunidos en Córdoba. ${ }^{12}$

En los años 1808 y 1809 nuevamente este sector fue requerido, esta vez con el objeto de socorrer a España, invadida por

9 IEA, Documento n. 6220.

10 Ibídem, Documento n..$^{\circ}$ 5693, 6069, 6221, 6238. AMC, Archivo Capitular, 1727 a 1866, Documentos incompletos, fols. 170 y 197.

11 AMC, 1726-1866, Municipalidad, documentos incompletos, fols. 167 a 209.

12 AHPC, 1808, Gobierno, Caja 30, fols. 108, 109. IEA, Documento n. ${ }^{\circ} 8936$. AMC, 1726-1866, fols. 210 a 214 . 
Napoleón. Muy remisos a estas pretensiones, los mercaderes contribuyeron con 4.000 pesos, expresando por medio del Cabildo la divergencia de miras e intereses con respecto a estos dispositivos financieros y su negativa a continuar aportando. Del mencionado total, 1.105 pesos fueron recaudados entre los comerciantes de origen español. ${ }^{13}$

Los acontecimientos de mayo de 1810 variaron tanto las situaciones como las opiniones, endureciendo posiciones. Consecuentemente las exigencias aumentaron, se comenzó a pensar en términos de economía de guerra, hombres y fortunas quedaron a disposición en la medida que la empresa político-militar lo necesitase, y fue entonces cuando comenzó el tiempo de las exacciones o requerimientos forzosos.

Conviene anotar que en Córdoba las medidas persecutorias de neto corte político dirigidas en desmedro de españoles no presentan ribetes conmocionantes, tales como las registradas en otras jurisdicciones. ${ }^{14}$ Pueden citarse algunas de carácter administrativo institucional, por caso la separación de los funcionarios españoles - capitulares o dependientes de administración de correos-, ${ }^{15}$ las disposiciones de este tipo dimanaron de funcionarios dependientes de los sucesivos "gobiernos nacionales". ${ }^{16}$ Por su parte las autori-

13 AHPC, 1809, Gobierno, Caja 31, fols. 437, 438. AMC, Actas Capitulares, Libros 43 y 44, págs. 496, 503, 505, Libros 45 y 46, págs. 60 a 63 y 86. IEA, Documento n. 9407. El Cabildo de Córdoba, integrado por comerciantes españoles, entre sus capitulares expresó: “...antes de ahora se han dado por este Ilustre Cuerpo y esta ciudad los donativos que por sus cortos medios podían para ello y aún excediéndose de los límites de la prudencia en atención al amor que profesan a su señor y rey Fernando VII, pero en la actualidad con la pérdida que ha tenido este comercio, especialmente el de mulas en más de dos millones de pesos que se les debe en Perú no se puede de ningún modo cobrar y que este giro se halla totalmente destrozado... en esta virtud por ahora es imposible tanto los donativos, como empréstitos que se le pedían...".

14 Confrontar con notas $n .^{\circ} 44,45$ y 46.

15 AHPC, 1810, Gobierno, Caja 32, fols. 240, 568. AMC, Libros 45 y 46, págs. 22, $301,366,418$ a $423,523$.

16 En AHPC, 1813, Gobierno, Caja 36, fols. 191, 210, 605 y Caja 38, fols. 388, 427; la misión Jonte-Ugarteche aplicó extrañamientos a mercaderes remisos a acatar sus directivas. En AHPC, Gobierno, Caja 40, fol. 375. 1811-1813, Protocolo de Escribanos, Registro n. ${ }^{\circ}$ 3, fols. 668 a 670, el comerciante español Manuel López fue confinado a 30 leguas de la ciudad de Córdoba. En AHPC, 1814, Gobierno, Caja 38, fols. 463-596, otro arresto y prisión según órdenes del Directorio. 
dades cordobesas no tomaron medidas que exhibieran el sesgo aludido en directo desdoro del sector comercial ibérico, por el contrario se detectan actitudes que dejan trascender ciertas consideraciones para con ellos.

Sin embargo, las sanciones de tipo económico recayeron sin menguas sobre el grupo mercantil español. A poco de producidos los hechos revolucionarios de 1810 , uno de los más enconados resistentes, el alcalde José García Piedra - acaudalado comerciante español- sufrió multas y embargos encubiertos formalmente como préstamos que determinaron su gradual empobrecimiento. ${ }^{17}$

A partir de los acontecimientos revolucionarios y en función de sus necesidades, comienzan a jalonarse una larga serie de exigencias financieras que, en una u otra manera o circunstancia, afectaron al comerciante ibérico y a su familia. No siempre es posible cuantificar estas operaciones, tal como aconteció con el empréstito de 12.000 pesos exigidos por el jefe de la expedición militar destinada a las regiones norteñas al atravesar territorio cordobés, del que sólo se conoce su resultante: el comercio de la ciudad prestó la suma de 8.834 pesos. $^{18}$

Una vez constituida la Asamblea de 1813, exigió un préstamo forzoso destinado a aliviar las cargas financieras que desde 1810 pesaban sobre la tesorería de Buenos Aires. De acuerdo a las proyecciones efectuadas, Córdoba debía recaudar 34.000 pesos. ${ }^{19}$ Por primera vez se establecieron las bases para la amortización del capital a prestarse, utilizando pagarés como instrumentos de cancelación de

17 Ibídem, 1810, Gobierno, Caja 32, fols. 256, 448. Caja 36, fols. 191, 210, 605, Caja 38, fols. 388, 422. AGN, Sala X, 5-2-6 y 5-3-3. Aunque cierta documentación de la época informe que estas medidas fueron dejadas sin efecto, en 1863 el Estado cordobés reconoció a sus herederos una deuda de 18.000 pesos, tomados en las siguientes fechas y montos: el 26 de agosto de 1810: 12.000 pesos y el 8 de octubre de 1810: 6.000 pesos; confrontar AHPC, 1863, Hacienda, Tomo 692, fol. 175.

18 AHPC, 1811-1818, Gobierno, Contaduría, Tomo I, fol. 28.

19 IEA, Documentos n. ${ }^{\circ} 10.290$ y 12.472. Los montos proyectados fueron: para Buenos Aires: 200.000 pesos; Mendoza y San Juan: 30.000 pesos; Córdoba: 34.000 pesos; La Rioja: 4.000 pesos; San Luis: 1.000 pesos. El resto sujeto a nuevos cálculos. 
deudas contraídas en concepto de derechos de aduana, reconociendo intereses que se graduaban del tres al seis por ciento, según la liquidación se efectuase un año después a la vista y al contado. ${ }^{20}$ Puede inferirse que la operación se pensó con el propósito de tomar del comercio la mayor parte del monto prestable, dado que constituía el único sector en condiciones de amortizarse saldando impuestos aduaneros. ${ }^{21}$ La suma reunida alcanzó 31.125 pesos, considerando que el sector mercantil cordobés estaba conformado - en esos años- en importante proporción por españoles, a ellos debe atribuirse una equivalencia en las cargas crediticias. ${ }^{22}$

\section{Empréstitos ordenados por el gobierno cordobés}

Dado que el dinero reunido no alcanzó para satisfacer el objetivo trazado, en 1814 el gobernador Viana dispuso otro empréstito proyectado con preferencia a receptar capitales comerciales, sector al que trató de estimular presentando la operación un tanto más atractiva al proponer como alternativa del metálico cierta producción de uso mercantil, específicamente ponchos eventualmente tasados en 8 reales, con ello recaudó 2.240 pesos, de los cuales 1.519 pesos fueron proveídos por españoles. ${ }^{23}$

20 Ibídem, Documento n. ${ }^{\circ} 12.472$.

21 AGN, Comisionados Jonte-Ugarteche a las Provincias Interiores 1813-1814, División Gobierno Nacional. Segreti, La misión...

22 AHPC, 1863, Hacienda, Tomo 692, fol. 177. No quedan constancias documentales de quienes suministraron ese dinero. Pero habiendo reconocido e informado a la Asamblea de 1813, los comisionados Jonte y Ugarteche que en Córdoba "...la clase comerciante ...en la mayor parte es de españoles europeos..."; confrontar AGN, Comisionados..., puede inferirse que éstos cargaron con el préstamo.

23 AHPC, 1814, Hacienda, Tomo 172, fols. 37, 38, 119 a 124, Tomo 178, fols. 81, 82, Tomo 207, fol. 127. Es posible que el sector comercial hubiera entregado más ponchos y frazadas, de no mediar una magnífica coyuntura mercantil con la plaza paraguaya; en efecto. en el Paraguay los ponchos se tasaban en 30 reales, precio muy superior a la cotización de la plaza de Córdoba, Confrontar IEA, Documentos n. ${ }^{\circ} 6277,6283,6284$. Estos precios reportaron a los comerciantes de Córdoba beneficios superiores al 600 por ciento, según cálculos de Moyano, Hugo: La organización de los gremios en Córdoba. Sociedad artesanal y producción artesanal 1810-1820, Córdoba, 1986, págs. 107 a 109. 
Para el indispensable mantenimiento de la fábrica de pólvora y armas, también se tomó del comercio un préstamo amortizable a los seis meses. Por este crédito sólo se obtuvo el 33,3\% de las sumas calculadas. En efecto, de los 19.000 pesos presupuestados se logró acreditar 6.428 pesos, ${ }^{24}$ mostrando una vez más que las expectativas gubernamentales se hallaron muy alejadas de las disponibilidades mercantiles.

A poco los mercaderes españoles fueron exigidos para otro empréstito forzoso, esta vez para financiar los sueldos de los diputados cordobeses destacados en el Congreso, dinero que debía amortizarse en el término de un año con un premio de cinco por ciento, tasa de interés aproximada a la usual en transacciones comerciales; esta cláusula facilitó un préstamo de 4.569 pesos. ${ }^{25}$

Durante 1815, el gobernador José Javier Díaz, de tendencia distinta a la autoridad directorial de las Provincias Unidas, protegió un tanto al sector afectado casi constantemente al crédito público, además entretuvo las urgencias de los gobernantes nacionales utilizando argumentos reales y concretos, tales como "...La suspensión del comercio de mulas que ha sido siempre el que formara la riqueza de esta provincia y el único ramo que hacía el ingreso al numerario preciso para el giro, como asimismo las pasadas exacciones, sin término ni medida, han escaseado en tal extremo la fortuna de todo el vecindario que basta ver la frugalidad con que se tratan aún los que conservan el concepto de pudientes para graduarla..... ${ }^{26}$

24 Registro Oficial de la República Argentina 1810-1821, Buenos Aires, 1879, Tomo I, págs. 298, 299. AHPC, 1815, Hacienda, Tomo 176, fols. 67, 131. Tomo 192, fol. 201. 1866, Hacienda, Tomo 193, fols. 17, 30, 54. Tomo 196, fols. 22, 196. 1815, Gobierno, Caja 44, fol. 442. IEA, Documento n. 8284.

25 AHPC, 1815, Hacienda, Tomo 193, fol. 5. Tomo 196, fols. 20, 25, 28, 97, 138, 146, 162. Tomo 197, fols. 23, 33, 81, 85, 99, 114, 166. 1815, Gobierno, Caja 45, fol. 70 .

26 IEA, Documento $n .{ }^{\circ} 9252$. El gobernador Díaz provenía de una familia de hacendados traficantes de mulas, razón por la que insistía en los perjuicios por la decadencia de este comercio. 


\section{Los créditos forzosos exigidos por el Congreso de Tucumán}

Quizás este corto respiro obtenido en 1815 provocó un efecto contrario en el siguiente año, induciendo a los diputados del Congreso al manejo del prejuicio referido a que los comerciantes europeos de Córdoba habían resultado menos gravados que los residentes en otros pueblos. ${ }^{27}$

En consecuencia resolvieron realizar un empréstito que montase 40.000 pesos, involucrando en la operación exclusivamente a españoles. El mismo debía amortizarse en fecha tan imprecisa como “...al año de establecida la paz general..." en el país y siempre que las circunstancias tendiesen a mejorar. ${ }^{28}$ En definitiva, al regularse y distribuirse los montos a prestar, las pretensiones disminuyeron a 34.000 pesos. $^{29}$

La recaudación del dinero resultó lenta, trabada por los forzados prestamistas, al extremo que la autoridad de turno debió apremiar ejecutivamente a algunos, embargar y hasta encarcelar a otros, en procura de finiquitar la operación crediticia. ${ }^{30}$

También los sucesos regionales de distinto caríz, provocaron efectos retardatarios en la operación, como consecuencia de las rebeliones locales destinadas a inclinar el péndulo de la política cordobesa en dirección al artiguismo y en contraposición al centralismo porteño. Estos alzamientos quitaron capacidad financiera a los prestamistas, quienes simultáneamente debieron solventar a la tesorería provincial requerida por las erogaciones imprevistas que los aludidos sucesos provocaron. ${ }^{31}$

27 Asambleas constituyentes argentinas, seguidas de los textos constitucionales, legislativos y pactos interprovinciales que organizaron políticamente la nación. Fuentes seleccionadas, coordinadas y anotadas en cumplimiento de la ley 11.857 por Emilio Ravignani, Tomo I, Años 1813-1833, pág. 195.

28 Ibídem, pág. 196.

29 AGN, Sala X, 5-3-4.

30 Asambleas constituyentes... págs. 247, 248. AHPC, 1816-1823, Contaduría-Copiadores, fol. 257. 1816, Gobierno, Caja 50, fols. 430, 431. Estas disposiciones se aplicaron a los comerciantes españoles Francisco Vásquez Maceda, Felipe Roca, Manuel López, Juan del Signo, Francisco Troncoso, Pelayo Antonio Gutiérrez y Francisco García.

31 Converso, Félix E.: La repercusión financiera de los movimientos de Juan Pablo Bulnes. "Labor de investigación", Córdoba, 1984, págs. 191 a 210. 
El préstamo exigido por el Congreso de Tucumán terminó de ingresar en las Cajas en 1818, calculándose el monto acreditado en 31.000 pesos. ${ }^{32}$ Esta suma fue invertida exclusivamente en gastos militares, tanto los generados por el mantenimiento del ejército del norte como los absorbidos por las milicias locales. ${ }^{33} \mathrm{Se}$ explica el destino de estos dineros al considerar que a partir de 1818 el gasto militar en la tesorería de Córdoba se acrecentó en una proporción del $28,3 \%$ en relación al año anterior, ${ }^{34}$ a causa de las erogaciones que provocó el mantenimiento de las divisiones de ejército que se instalaron en territorio cordobés con motivo de las guerras civiles y que definieron a los últimos años fiscales de la década como muy gravitados por dichos desembolsos.

\section{CUADRO N. ${ }^{\circ} 2$}

\section{VARIACIÓN PORCENTUAL: GASTOS MILITARES - INGRESOS GENERALES Y GASTOS PÚBLICOS EN CÓRDOBA}

\begin{tabular}{ccc} 
Años & Ingresos generales & Gasto público \\
\hline 1817 & $31,3 \%$ & $36,6 \%$ \\
1818 & $57,6 \%$ & $60 \%$ \\
1819 & $46,5 \%$ & $48,1 \%$
\end{tabular}

Fuente: Elaboración propia según documentos citados en nota 34.

En 1819, otro préstamo forzoso destinado a solventar parte del ejército del norte destacado en Córdoba, demandó al comercio un total de 18.000 pesos. ${ }^{35}$ Durante dicho año nuevamente el Congre-

32 AHPC, 1813-1816, Gobierno-Copiadores, fol. 257. 1816, Caja 49, fols. 349, 417. Caja 50, fol. 432. 1816-1823, Gobierno Contaduría, Tomo 1, fol. 24. 1816, Hacienda, Tomo 192, fol. 124. 1817-1819, Gobierno-Copiadores, fol. 449.

33 Ibídem, 1816-1823, Gobierno, Tomo 1, fols. 129, 137, 141, 142, 179 a 181. AGN, Córdoba, Gobiemo, Sala X, 5-3-3.

34 AHPC, Hacienda, Tomos 206, 216 y 243.

35 Ibídem, 1819, Gobierno, Caja 60, fols. 101, 109. 1819, Hacienda, Tomo 225, fols. 281, 287, 288. 1816-1823, Gobierno, Tomo 1, fol. 203. 
so impuso otro empréstito forzoso a los españoles residentes en Córdoba, acreditándose 11.896 pesos. ${ }^{36}$

\section{¿Deterioro económico del sector mercantil español?}

La coyuntura política, militar y económica que conlleva el sistema de paliar las angustias del erario mediante el crédito público, perjudica aparentemente a los afectados en grado diverso. Los testimonios relevados - todas fuentes cualitativas, algunas emanadas del ámbito oficial- diseñan situaciones penosas para la población en general y de efectos perniciosos en el sector del comercio, más asiduamente exigido. ${ }^{37}$

No debe negarse que el segmento de la corporación que resultó más afectado fue el español y su familia americana, ${ }^{38}$ tampoco pueden rehusarse casos muy puntuales o determinados de menoscabo y deterioro económico, pero asimismo conviene estimar la existencia de indicadores que apuntan a otra realidad menos perjudicial y desdorosa.

Obsérvese en el Cuadro n. ${ }^{\circ} 3$, los montos empleados en exportación de mercancía y aquellos invertidos en importación, que el sector mercantil de Córdoba manejó a lo largo de la década de 1810 en la que se realizaron los préstamos en cuestión. Este movimiento de capitales no permite pensar en un deterioro tan considerable que determinase inconvenientes en el intercambio, por el contrario el comercio continuó su giro y sus inversiones prosiguieron activas.

La caída en las exportaciones que se evidencia en los últimos años del decenio, debe atribuirse a la obstrucción del tráfico mer-

36 Ibídem, 1819, Hacienda, Tomos 242 y 243 . IEA, Documento n.. 5287.

37 IEA, Documentos n. ${ }^{\circ} 6277,9539$. AHPC, 1817, Gobierno, Caja 52, fols. 249 a 258, 284, 289 a 294. 1818, Caja 58, fols. 113 a 123. Caja 72, fol. 257. 1819, Gobierno, Caja 59, fols. 40, 408. AGN, Córdoba, Gobierno, Sala X, 5-3-3. AMC, Actas, Libro 49, págs. $229,230$.

38 Converso, Españoles y americanos...; de acuerdo a este artículo, los vínculos establecidos por el comerciante español fueron tan estrechos como para pensar en la repercusión que puede haber provocado en un vasto sector de la sociedad cordobesa el deterioro económico de algún mercader ibérico. 
cantil con el litoral a causa de la situación bélica y a las secuelas del desmembramiento del mercado virreinal, ${ }^{39}$ no a la carencia de capitales destinados al intercambio por haber sido transferidos al crédito público. En todo caso este traspaso involucró sumas indiscutiblemente menores.

\section{CUADRO N. ${ }^{\circ} 3$}

MONTOS EMPLEADOS EN IMPORTACIÓN Y EXPORTACIÓN POR EL COMERCIO DE CÓRDOBA (EN PESOS DE OCHO REALES)

Año Importación Exportación

\begin{tabular}{lrr}
\hline 1810 & 33.631 & 202.649 \\
1811 & 8.450 & 113.755 \\
1812 & 119.386 & 163.655 \\
1813 & 30.054 & 147.117 \\
1814 & 64.516 & 133.163 \\
1815 & 65.856 & 201.885 \\
1816 & 184.238 & 139.231 \\
1817 & 172.346 & 187.541 \\
1818 & 102.345 & 90.653 \\
1819 & 205.516 & 74.022 \\
\hline
\end{tabular}

Fuente: Elaboración propia, según datos de nota 39.

Al comparar los montos aportados al crédito público por los mercaderes españoles -que las fuentes han permitido reconstruir(confrontar cuadro n. ${ }^{\circ} 4$ ) con el capital en giro mercantil (confron-

39 El cuadro n. 3 se elaboró en base a los datos aportados en Lobos, La Revolución y el comercio interior..., para los montos empleados en el tráfico de exportación. En tanto que los montos de inversión en bienes de consumo y capital para importación, se tomaron de Converso, Las relaciones del intercambio... A los fines del análisis, debe considerárselos instrumentalmente como indicadores confiables, no obstante las dificultades y falencias que presentan las fuentes, en ambos casos. 
tar cuadro n." 3), si bien su proporcionalidad con el total acreditado no carece de importancia, teniendo presente que el sector espanol constituía la mayor parte de los agentes del mercado, ${ }^{40}$ esos montos prestados pierden la entidad que puede habérseles atribuido como causales de un considerable perjuicio económico.

$$
\text { CUADRO N. }{ }^{\circ} 4
$$

MONTOS PRESTADOS POR EL COMERCIO DE CÓRDOBA EN GENERAL Y ESPAÑOLES EN PARTICULAR. TOTALES APROXIMADOS (EN PESOS DE OCHO REALES) ${ }^{41}$

\begin{tabular}{lrc} 
Año & $\begin{array}{c}\text { Comercio } \\
\text { en general }\end{array}$ & $\begin{array}{c}\text { Comerciantes } \\
\text { españoles }\end{array}$ \\
\hline 1806 & 6 a 7.000 & 6.000 \\
$1808-9$ & 4.000 & 1.105 \\
1810 & 8.830 & Sin datos \\
1812 & 11.250 & Sin datos \\
1813 & 31.125 & 31.125 \\
1814 & 2.240 & 1.519 \\
1815 & 11.428 & Sin datos \\
1816 & 23.000 & 23.000 \\
1817 & 2.800 & 700 \\
1818 & 8.000 & 8.000 \\
1818 & 4.640 & Sin datos \\
1819 & 29.896 & 20.436 \\
1820 & - & 4.217
\end{tabular}

Fuente: Elaboración propia, según datos de nota 41.

40 Confrontar nota $n .^{\circ} 22$.

41 IEA, Documentos n." 5693, 6096, 6238, 9407. AHPC, 1809, Gobierno, Caja 31, fols. 437, 438. 1816, Caja 49, fols. 349, 417, Caja 50, fol. 432. 1816-1823, Tomo 1, fols. 24, 203, 124. 1817-1819, Gobierno, fol. 449. 1820, Caja 70, fols. 28 a 35. Hacienda, tomos 92, 172, 178, 206, 216, 225, 243, 245, 259, 273. 1863, Hacienda, tomo 692, fol. 177. 
Además existen comprobaciones que permiten mostrar que algunas operaciones denunciadas por el grupo mercantil como exacciones en especie o mercancía, no fueron tales sino verdaderas transacciones comerciales, en las cuales los agentes del mercado actuaron como proveedores del Estado suministrándole ponchos, frazadas, mulas y caballos destinados a los ejércitos a lo largo de toda la década de 1810 , bienes que fueron comercializados por cantidades importantes. ${ }^{42}$

Asimismo, se conservan comprobantes de ventas documentadas efectuadas por distintos mercaderes, operaciones por las que se proveyó al Estado provincial de telas para uniformar a los regimientos, lo mismo que cueros y suelas destinadas a calzados y monturas. ${ }^{43}$

Otra pauta a la que conviene prestar atención es el acrecentamiento patrimonial de algunos mercaderes españoles (confrontar cuadro n. ${ }^{\circ}$ 1), que a juzgar por el período cronológico en el que se produjo el crecimiento, puede colegirse que coincide con el lapso en que arreciaron las exigencias crediticias. En estos casos es imposible afirmar qué determinantes de deterioro económico resultaron.

A ello debe agregarse que en Córdoba no se legisló normativa alguna que prohibiese o coartase de alguna manera el libre ejercicio de la actividad mercantil en que pudieran intervenir extranjeros, tal como sucedió en otras jurisdicciones, por caso Corrientes. ${ }^{44}$ Asi-

42 Converso, Félix E.: Los recursos de los comerciantes de Córdoba ante los requerimientos de las guerras de la independencia. Guerra y especulación, en el marco de una economía restringida, ponencia considerada en las "Sextas Jornadas de Historia Económica". Vaquerías, Córdoba, 1984 (mimeo). En 1812 facturaron 11.823 pesos en ponchos y 14.000 pesos en mulas. En 1814, se cobraron 5.500 pesos por venta de mulas al gobierno de Córdoba. Hasta 1819 se continuó proveyendo al Estado de ponchos y frazadas.

43 AHPC, 11819, Hacienda, Tomo 230, fols. 102 a 104, Tomo 270, fol. 72, Tomo 273, fol. 199. Por caso, Manuel de la Lastra, de la casa Fragueiro, fue activo proveedor del Estado. Otros ejemplos de proveeduría pueden confrontarse en: Moyano, La organización..., págs. 112 a 127.

44 Chiaramonte, Juan Carlos: Mercados de mercancías, mercado monetario y mercado de capitales, en el litoral argentino de la primera mitad del siglo XIX: el caso Corrientes. "Siglo XIX, Revista de Historia", Monterrey, México, 1987, Año II, n, ${ }^{\circ}$ 4, pág. 83. Tambien del mismo autor, Mercaderes del Litoral, Economía y Sociedad en la provincia de Corrientes, primera mitad del siglo XIX. Buenos Aires, 1991. 
mismo, pueden citarse los intentos mendocinos en ese sentido y también las pretensiones más extremas de los sanjuaninos no sólo destinadas a evitar que el comerciante foráneo ejerciera su oficio en su región, sino a extenderlo a conciudadanos argentinos originarios de otras provincias. ${ }^{45} \mathrm{Al}$ continuar en este terreno temático no pueden omitirse las persecuciones políticas acontecidas en Buenos Aires, que redundaron en perjuicio de sus mercaderes. ${ }^{46}$

En la región mediterránea, la libertad de comerciar no se coartó. Parece acertado atribuir este proceder a la necesidad de evitar perjuicios al mercado regional, en que tantos vínculos ligaron a familias de comerciantes ibéricos y americanos.

Un distinto aspecto que es necesario tratar con cierto cuidado es el referido a la involución numérica del grupo español del comercio. No conviene confundir el paulatino recambio generacional naturalmente acontecido en la población mercantil española, que empezó a asomar al unísono con los años veinte, presentando el comienzo de la disminución cuantitativa del agente español, ${ }^{47}$ con su presunta desaparición en el espacio del intercambio a causa del deterioro económico atribuido a las exacciones aplicadas en la década de 1810. De hecho, revisando los censos y listas impositivas se constata que aquellos comerciantes españoles en edad de continuar su actividad persistieron en la misma y algunos con buena fortuna. Importa entonces ponderar, en este hito cronológico, la declinación vegetativa más que las pautas de menoscabo económico como una causa de la desaparición en el mercado regional de determinados comerciantes españoles.

Resta otro aspecto por analizar, es el referido a las amortizaciones de los capitales prestados. De los empréstitos tomados en 1810 , se conservan constancias de devolución, que permiten afirmar que se cumplieron en casi su totalidad. No sucede lo mismo con los comprobantes de amortización del préstamo tomado por la "expedi-

45 Segreti, Carlos S. A.: La economía del interior en la primera mitad del siglo XIX: Cuyo. (Correlación de documentos). Academia Nacional de la Historia, Buenos Aires, 1981, págs. 21 a $26.85,86$.

46 Galmarini, La situación...

47 AHPC, 1820, Gobierno, Caja 70, fols. 28 a 35. 1822, Censo, Ciudad. 
ción auxiliadora" en el mencionado año. En tanto puede verificarse el saldo del crédito tomado en 1813, devuelto - en su mayor parte- entre los años 1814 y 1815 por la tesorería nacional en Buenos Aires, mediante el procedimiento del endoso de los certificados a comerciantes porteños de acuerdo a la práctica del descuento en su favor, con este premio ellos se encargaron de tramitar y lograr su cobro. ${ }^{48}$ Estas transferencias de documentos al cobro sólo se explican como consecuencia de transacciones mercantiles.

Las operaciones crediticias emanadas de autoridades cordobesas, se amortizaron - no sin dificultad - mediante el procedimiento de descuento o pago de deudas aduaneras, con la consuetudinarias pérdidas que estos traspasos de documentos ocasionaban. ${ }^{49}$

Asimismo el empréstito forzoso ordenado por el Congreso de Tucumán, se amortizó entre los años 1818 y 1822 a través de la tesorería provincial, de acuerdo a sus posibilidades financieras. ${ }^{50}$ Estas amortizaciones no cubrieron la totalidad de las sumas prestadas y tampoco se lograron sin salvar numerosos inconvenientes, particularmente en lo relativo a los montos acreditados en 1819. ${ }^{51}$

La contabilidad de la época resulta deficiente e incompleta, aún así afortunadamente existen indicadores que permiten reflexionar sobre la magnitud de la pérdida o perjuicio sufrido por los prestamistas del decenio 1810-1820.

Cuando en los años sesenta, como consecuencia de un tratado de reconocimiento entre España y la República Argentina, los herederos de aquellos mercaderes españoles sujetos a la referida política financiera reclamaron del gobierno de Córdoba - haciendo uso de sus derechos- el reconocimiento de estas deudas, se ordenó una investigación contable que demandó otra década — producto no sólo de la intrincada búsqueda sino también de la rémora burocrática-; por fin en 1878 un informe oficial reconoció una deuda por

48 Converso, Las relaciones del intercambio...

49 AGN, Sala X, 2-9-3.

50 AHPC, 1814, Hacienda, Tomo 207, fol. 127. 1816, Tomo 193, fols. 30, 31. 1817, Tomo 196, fols. $25,85,99,138,171$, Tomo 197, fol. 60 , Tomo 214 , fol. 71 .

51 Ibídem, 1818, Hacienda, Tomo 225, fols. 45 a 48. 1822, Tomo 274 , fols. 1018 a 1026, Tomo 259, fols. 101 a 103, 1818, Gobierno, Tomo 3, fols. 43, 44, Caja 51, fol. 35. 
los créditos tomados entre los años 1810 y 1820 inclusive que totalizó $15.816,25$ pesos, ${ }^{52}$

De acuerdo a la reconstrucción de los montos prestados (confrontar cuadro n. ${ }^{\circ} 4$ ), el total adeudado por el dinero tomado a comerciantes españoles en los años mencionados sumó 90.052 pesos - aunque no es aventurado presumir una cantidad mayor-, sin contabilizar los 18.000 pesos embargados a José García Piedra que debe considerarse una medida punitiva en vez de una operación crediticia. Entonces la fracción sin amortizar aparece como proporcionalmente pequeña, un 17,5 por ciento del total, habiéndose amortizado un 82,5 por ciento. Proporciones estas que tienden a morigerar la entidad del daño causado a los prestamistas.

Ha quedado expresado que esta población española no desapareció del mercado, sino de manera paulatina a lo largo de las décadas de 1820 y 1830 . Teniendo presente que, como consecuencia de los aprestos militares generados en las guerras civiles que incidieron sobre los ingresos generales y en el gasto público provincial (confrontar cuadro $n .^{\circ}$ ) que determinaron una larga lista de créditos públicos tomados por los sucesivos gobiernos (confrontar cuadro $n .^{\circ} 6$ ), es procedente plantear la verificación relativa a la continuidad de la capacidad financiera del sector o de la parte aún activa del mismo.

52 Ibídem, 1878, Gobierno, Contaduría, Tomo 3, fols. 42 a 44 . Véase apéndice. "Acreedores de la deuda española pagada por el gobierno nacional en 1868".

$\begin{array}{lclc}\text { Campillo, Florencio } & 471,75 & \text { Ordóñez, Manuel } & 247,50 \\ \text { Carreras, Juan y Bartolomé } & 920 & \text { Sánchez Osorio, Venancio } & 30 \\ \text { Díaz, Tomás } & 413 & \text { Porto, Manuel } & 95 \\ \text { Eguiluz, José } & 20 & \text { Palma, Juan } & 37 \\ \text { Echegaray, Miguel Ángel } & 70,87 & \text { Pruneda, Manuel } & 251 \\ \text { González, Felipe A. } & 558,50 & \text { Peiteado, Ignacio } & 235,81 \\ \text { Garzón, José } & 112,50 & \text { Ríos, Manuel } & 50 \\ \text { González, Francisco } & 6 & \text { Rueda, Benito } & 3.735 \\ \text { Yofre, José } & 712,50 & \text { Roca, Felipe } & 660 \\ \text { López, Manuel } & 2.195 & \text { Recalde, Francisco } & 1.921,90 \\ \text { López, Andrés } & 20 & \text { Ramos, Pedro Antonio } & 211,25 \\ \text { Vásquez Maceda, Francisco } & 2.687,50 & \text { Saráchaga, Juan Antonio } & 187,50 \\ \text { Niz, Pedro } & 105 & \text { Signo, Juan } & 1.401 \\ & & \text { Zavalía, Benito } & 285\end{array}$


CUADRO N. ${ }^{\circ} 5$

INCIDENCIA PORCENTUAL DE LA EROGACIÓN MILITAR EN LOS INGRESOS GENERALES Y EN EL GASTO PÚBLICO ${ }^{53}$

\begin{tabular}{cccccc} 
Año & $\begin{array}{c}\text { Ingresos } \\
\text { generales }\end{array}$ & $\begin{array}{c}\text { Gasto } \\
\text { público }\end{array}$ & Año & $\begin{array}{c}\text { Ingresos } \\
\text { generales }\end{array}$ & $\begin{array}{c}\text { Gasto } \\
\text { público }\end{array}$ \\
\hline 1820 & 65,2 & 66,4 & 1828 & 45,2 & 46,2 \\
1821 & 55,4 & 55,6 & 1829 & 76,1 & 76,3 \\
1822 & 65,4 & 66,2 & 1830 & 70,8 & 70,9 \\
1823 & 63,2 & 67,7 & 1831 & 59,9 & 60 \\
1824 & 63,4 & 65,9 & 1832 & 57 & 57,4 \\
1825 & 59,1 & 59,1 & 1833 & 61,3 & 61,5 \\
1826 & 48,9 & 49,4 & 1834 & 61,2 & 61,5 \\
1827 & 53,2 & 53,4 & 1835 & 51,3 & 51,4
\end{tabular}

Fuente: Elaboración propia, según datos de nota 53.

CUADRO N. ${ }^{\circ} 6$

CRÉDITO PÚBLICO 1820-1833 (EN PESOS DE OCHO REALES)

Tomado del

Años sector mercantil

\begin{tabular}{lr}
\hline 1820 & 30.531 \\
1821 & 9.526 \\
1827 & 18.760 \\
1828 & 5.615 \\
1829 & 73.454 \\
1830 & 7.238 \\
1831 & 55.603 \\
1832 & 717 \\
1833 & 15.000 \\
\hline
\end{tabular}

Fuente: Elaboración propia, según nota 53.

53 Ibídem, Hacienda, Tomos 254, 265, 277, 289, 301, 314, 323, 333, 348, 358, 384, $397,409,430$ a 432. 
Sólo en contadas operaciones ha resultado posible rescatar algunas listas de prestamistas y de ellas rehacer la correspondiente a los mercaderes españoles; con esta información a la mano se posibilitó el cálculo de algunos préstamos efectuados por el sector, muestreo que permite una idea de su capacidad y vigencia financiera (confrontar cuadro . $^{\circ} 7$ ).

CUADRO N. ${ }^{\circ} 7$

ALGUNOS PRÉSTAMOS TOMADOS DE COMERCIANTES ESPAÑOLES (EN PESOS DE OCHO REALES) ${ }^{54}$

\begin{tabular}{ccc} 
Año & $\begin{array}{c}\text { Total } \\
\text { Acreditado }\end{array}$ & $\begin{array}{c}\text { Prestado por } \\
\text { españoles }\end{array}$ \\
\hline 1821 & 2.890 & 870 \\
1827 & 14.260 & 3.075 \\
1827 & 1.700 & 500 \\
1828 & 5.615 & 1.154 \\
1829 & 6.145 & 1.374 \\
1830 & 17.770 & 4.695
\end{tabular}

Fuente: Elaboración propia, según nota 54.

\section{Consideraciones últimas}

Lo expuesto permite pensar que aquellos comerciantes españoles sobre quienes recayeron empréstitos forzosos s exacciones durante la década de 1810 , se vieron en alguna medida afectados, pero no al extremo de impedirles continuar su giro mercantil y en ciertos casos lograr un interesante acrecentamiento patrimonial. Con el

54 Ibídem, Hacienda, Tomos 269, 328, 329, fols. 369, 375, Tomo 339, fols. 49, 306, Tomo 355, fol. 38, tomos 356 y 359. Gobierno, 1824-1829, Tomo 1, fols. 366, 367. IEA, Documentos n. ${ }^{\circ}$ 944, 1040, 12.302, 12.303. Gobierno, 1829, Tomo 1, fols. 554, 555. 
correr del tiempo consiguieron - aunque con pérdidas - recuperar parte de sus capitales prestados mediante las amortizaciones concretadas en distintas épocas por los tesoros nacional y provincial.

De manera tal que el deterioro sufrido - cuando lo hubo- resultó superable en el corto plazo y sólo en determinados casos muy puntuales y escasos en número el resultado fue patrimonialmente dañoso. ${ }^{55}$.

Al detectar algún daño económico, se percibe que fue determinado por distintas causas, tales como el entorpecimiento del tráfico mercantil provocado por los diversos enfrentamientos bélicos, tanto en las regiones norteñas como posteriormente en las litoraleñas. El consecuente fracaso de sus negocios y quiebras de sociedades conllevaron explicables pérdidas de capitales, ${ }^{56}$ que sumadas a los requerimientos formulados desde los gobiernos, dieron lugar a los lamentos tan peculiares al gremio.

No se encuentran evidencias fehacientes o confiables que permitan concluir que la práctica financiera aplicada mediante los préstamos forzosos constituyó el único y determinante perjuicio económico en el sector mercantil español residente en Córdoba, que si lo hubo sólo afectó a agentes del mercado en casos muy puntuales.

Por último, no parecen surgir importantes diferencias en los procedimientos a los criterios empleados por los gobiernos para canalizar hacia el erario público un flujo de capitales necesario para paliar sus constantes crisis. Tanto antes como después de la revolución de 1810 , se sucedieron las técnicas puestas en práctica por distintas administraciones sin variantes significativas. Quizás ésta pueda atribuirse a la restricción financiera casi crónica de estas economías. Por su parte, los prestamistas también conservaron una actitud invariable presentando reticencias previas a acceder a algún préstamo dinerario al Estado y quizás con mayor aquiescencia cuando se comprobó el cumplimiento de ciertas cláusulas de amortización.

55 El más evidente y conocido, es el citado caso de José García de la Piedra.

56 AHPC, 1808-1810, Protocolo de Escribanos, Registro n. ${ }^{\circ} 4$, fols. 570 a 574.1811 1813, Registro n." 4, fols. 9 a 11, 126, 127, 253, 254, 479 a 482. AGN, Comisionados Ugarteche y Jonte. AHPC, 1818-1819, Registro n. ${ }^{\circ} 4$, fols. 340, 241. 1820-1822, Registro n." 4, fols. 9 y 10. 


\section{Apéndice *}

Del tratado de reconocimiento, paz y amistad celebrado entre la $\mathrm{Re}$ pública Argentina y el reino de España el 6 de septiembre de 1863 y ratificado el 5 de noviembre de ese mismo año, interesan los siguientes artículos:

“4. - - La Confederación Argentina considerando que así como adquiere los derechos y privilegios correspondientes a la Corona de España, contrae todos sus deberes y obligaciones, reconoce solemnemente como deuda consolidada de la República tan privilegiada como la que más conforme a lo establecido espontáneamente en sus leyes, todas las deudas, de cualquiera clase que sean contraídas por el gobierno español y sus autoridades en las antiguas Provincias de España que forma actualmente o constituyan en lo sucesivo el territorio de la República Argentina, evacuado por aquellos en 1810.

Serán considerados como comprobantes de las deudas, los asientos de los libros de cuentas y razón de las oficinas del antiguo virreinato de Buenos Aires o de las especiales de las provincias que constituyen o formen en adelante la República Argentina, así como los ajustes y certificaciones originales o copias legítimamente autorizadas y todos los documentos que cualesquiera sean sus fechas hagan fe con arreglo a los principios de derecho universalmente admitidos siempre que estén firmados por autoridades españolas residentes en el territorio.

La calificación de estos créditos se hará oyendo a las partes interesadas y a las cantidades que esta liquidación resulte admitidas y de legítimo pago devenguen el interés legal correspondiente, desde un año después de canjeadas las ratificaciones del presente tratado, aunque la liquidación se verifique con posterioridad.

5. - - Aunque las luchas y desavenencias felizmente no fueron tenaces y desastrosas en el antiguo virreinato de Buenos Aires y es de presumir por consiguiente que hayan sido insignificantes los secuestros y confiscaciones de propiedades de súbditos españoles o a ciudadanos argentinos, deseando evitar todo el daño la República Argentina y Su Majestad Católica, se comprometen solemnemente a que todos los bienes muebles o inmuebles, alhajas, dinero u otros efectos de cualquiera especie que hu-

* AHPC, 1863, Hacienda, fols. 182 a 186. 
bieren sido secuestrados o confiscados a súbditos españoles, a ciudadanos de la República Argentina, durante la guerra sostenida en América o después de ella y se hallaren todavía en poder de los respectivos gobiernos en cuyo nombre se hubiese hecho tal secuestro o la confiscación serán inmediatamente restituidos a sus antiguos dueños o a sus herederos o legítimos representantes sin que ninguno de ellos tenga acción para reclamar cosa alguna por razón de los productos que dichos bienes o valores hayan podido rendir, durante el secuestro o confiscación. Los desperfectos o mejoras causados en tales bienes por el tiempo o por el acaso, durante el secuestro o la confiscación, no se podrán reclamar ni por una ni por otra parte, pero los antiguos dueños y sus representantes deberán abonar al gobiemo respectivo todas aquellas mejoras hechas por la obra humana en dichos bienes u efectos, después del secuestro o confiscación, así como el expresado gobierno deberá abonarles todos los desperfectos que provengan de tal obra en la mencionada época. Y estos abonos recíprocos se harán de buena fe y sin contienda judicial, a juicio amigable de peritos o de arbitradores nombrados por las partes y terceros que ellos elijan en caso de discordia. A los acreedores cuyos bienes hayan sido vendidos u enajenados de cualquier modo se les dará la indemnización competente a estos términos y a su elección, o un papel de deuda consolidada de la clase más privilegiada cuyo interés empezará a correr al cumplirse el año de canjeados las satisfacciones del presente tratado o en tierras del Estado. Si la indemnización tuviese lugar en papel se dará al interesado por el gobierno respectivo un documento de crédito contra el Estado que devengará un interés desde la época que se fija en el párrafo anterior, aunque el documento fuese expedido con posterioridad a ella, y si se verificase en tierras públicas, después del año siguiente al cambio de ratificaciones, se añadirá al valor de las tierras públicas que se den en indemnización de los bienes perdidos la cantidad de tierras que se calcule equivalente al rédito de las primitivas que se hubiesen entregado al año del referido canje... Para la indemnización tanto en papel como en tierras del Estado se atenderá el valor que tienen los bienes confiscados al tiempo del secuestro..." 